\begin{tabular}{|l|l|l||}
\hline \multicolumn{2}{|c|}{ PublisherInfo } \\
\hline \hline PublisherName & $:$ & BioMed Central \\
\hline \hline PublisherLocation & $:$ & London \\
\hline \hline PublisherImprintName & $:$ & BioMed Central \\
\hline \hline
\end{tabular}

\title{
Proliferation markers in preinvasive breast lesions
}

\begin{tabular}{||l|l|l||}
\hline \multicolumn{2}{|c||}{ ArticleInfo } \\
\hline \hline ArticleID & $:$ & 3619 \\
\hline \hline ArticleDOI & $:$ & $10.1186 /$ bcr-1999-66597 \\
\hline \hline ArticleCitationID & $:$ & 66597 \\
\hline \hline ArticleSequenceNumber & $:$ & 39 \\
\hline \hline ArticleCategory & $:$ & Paper Report \\
\hline ArticleFirstPage & $:$ & 1 \\
\hline \hline ArticleLastPage & $:$ & 4 \\
\hline \hline & $:$ & RegistrationDate : 1999-8-2 \\
ArticleHistory & $:$ & OnlineDate \\
\hline \hline ArticleCopyright & $:$ & Current Science Ltd1999-8-2 \\
\hline \hline ArticleGrants & $:$ & \\
\hline \hline ArticleContext & $:$ & 1305811 \\
\hline \hline
\end{tabular}




\section{Keywords}

Ki67/MIB-1, p53, Bcl-2, hyperplasia, carcinoma in situ, normal breast, immunohistochemistry

\section{Introduction}

A number of in situproliferations are associated with an increased risk of developing carcinoma; this risk increases with the severity of cytological atypia. A multistep process may exist in the progression from one lesion to another. In this proposed model the control of cell proliferation and of apoptosis may be important. The markers Ki67/MIB-1, Bcl-2 and p53 were therefore studied in normal and precancerous breast tissue.

\section{Aims}

To determine whether modulation of proliferative activity and apoptotic control occurs in normal breast, breast hyperplasia, atypical hyperplasia and carcinoma in situ.

\section{Comments}

There is growing evidence that breast cancer arises through a number of different genetic pathways. One possible pathway proceeds from normal tissue to invasive cancer via a multistep pathway progressing through hyperplasia without atypia, atypical hyperplasia and low grade in situ neoplasia. Cytologically similar precursor lesions for high grade ductal carcinoma in situ have not been identified in the breast and thus these lesions possibly arise de novo or progress so rapidly that precursor lesions cannot be identified. The present study has looked at a variety of in situ proliferations and immunoprofiled these lesions using proliferation- and apoptosis-related markers. The finding of similar immunophenotypes amongst morphologically similar and dissimilar lesions with categorisation into groups is interesting and lends further support to the precancerous nature of the in situ proliferations.

\section{Methods}


Formalin-fixed and paraffin-embedded sections of the following lesions were studied: 365 normal lobules; 150 small ducts; 35 florid ductal hyperplasias; 8 atypical ductal hyperplasias; 12 atypical lobular hyperplasias; 14 poorly differentiated, 20 intermediately differentiated and 12 well differentiated ductal carcinomas in situ and 12 lobular carcinomas in situ. Standard immunohistochemistry methods were used and the results were scored subjectively in a semiquantitative manner. A $10 \%$ cutoff value was used to define p53 and Bcl-2 positivity and to define groups with high or low levels of proliferation.

\section{Results}

All of the florid and atypical ductal hyperplasias, the lobular in situ neoplasias and the welldifferentiated ductal carcinomas in situ showed low levels of proliferation, high levels of Bcl-2 expression and low or absent p53 expression levels. Most of the normal breast lobules and ducts had a similar immunoprofile although a small subset (approximately 10\%) contained a high number of proliferating cells and showed low levels of Bcl-2 expression. In contrast poorly differentiated ductal carcinomas in situhad a high proliferation rate (100\%), showed low levels of expression of Bcl-2 (93\%) and were p53-positive (85\%). Intermediately differentiated ductal carcinomas were a heterogeneous group and had a mixture of positive and negative lesions for the three markers, with MIB-1 positivity being seen in $50 \%$, Bcl-2 in $70 \%$ and p53 in 30\%.

\section{Discussion}

In this study, three different groups of lesions have been identified by using immunohistochemical profiling for MIB-1, p53 and Bcl-2. The first group contains florid and atypical ductal and lobular hyperplasias, well-differentiated ductal carcinoma in situ and lobular carcinoma in situ. The second group contains poorly differentiated ductal carcinoma in situ, whereas the third group shows heterogeneous staining and contains intermediate ductal carcinoma in situ. Two possible models of neoplastic progression could explain these results. In the first model, progression could occur from the group containing the well-differentiated ductal carcinoma in situ to intermediate and finally to poorly differentiated ductal carcinoma in situ with a progressive increase in both proliferation and p53 expression and loss of Bcl-2 expression. An alternative model suggests that low grade ductal carcinomas and lobular carcinomas in situare derived from the florid and atypical hyperplasias as they share a common immunohistochemical phenotype, whereas poorly differentiated ductal carcinomas arise from a separate pathway, possibly from the small percentage of normal ducts which have a high proliferative rate and show decreased Bcl-2 expression. The intermediately differentiated ductal carcinomas possibly represent lesions which overlap the two groups. 


\section{References}

1. Viacava P, Naccarato AG, Bevilacqua G: Different proliferative patterns characterize different preinvasive breast lesions. J Pathol. 1999, 188: 245-251.

This PDF file was created after publication. 